\title{
TERRORISMO Y DERECHO PENAL Del derecho penal como instrumento de última ratio al derecho penal del enemigo \\ TERRORISM AND CRIMINAL LAW \\ From a criminal law concept as extrema ratio to enemy criminal law
}

\author{
Elisabetta Cutrale*
}

RESUMEN: La agresión terrorista ha supuesto, a nivel nacional y internacional, el problema de la creación de un sistema penal de reacción a tal fenómeno. Sin embargo, la necesidad de una contestación urgente ha tenido como consecuencia una incertidumbre general que lleva en sí misma el riesgo de la negación del Estado de derecho para adoptar la lógica del derecho penal del enemigo. Este escrito -a través el análisis de la teoría de Gunther Jakobs, teórico del derecho penal del enemigo- describe las repercusiones, parafraseando a Ferrajoli, de una falta de "asimetría entre Estados de derecho y violencia extra legal".

ABSTRACT: The fear of terrorism has created, at national and international level, a criminal law system to react to this phenomenon. The need for a rapid answer to the problem has led to legal uncertainty that carries with it the risk of the negation of the legal state to adopt the logic of the enemy's criminal law. This writing, through the analysis of the theory by Gunther Jakobs, theorist of the enemy's criminal law, describes which are the negative repercussions of a lack of "asymmetry between legal state and extra legal violence" mentioning Luigi Ferrajoli.

PALABRAS CLAVE: ciudadano,enemigo, pena, derecho penal,Estado de derecho.

KEYWORDS: Citizen, enemy, punishment, criminal law, legal state.

Fecha de recepción: 26/11/2019

Fecha de aceptación: 13/12/2019

doi: https://doi.org/10.20318/universitas.2020.5139

* Licenciada en Derecho. Máster en Derechos Humanos y Relaciones Internacionales
por SIOI Roma (Sociedad Italiana para las Relaciones Internacionales). E-mail:
elisabetta.cut@gmail.com 


\section{1.- EL DERECHO PENAL DEL ENEMIGO}

El fenómeno del terrorismo internacional, en particular después del 11 de septiembre 2001 y el 11 de marzo 2004, ha creado inseguridad y una aceleración en las tendencias de la sociedad a enfatizar el riesgo concreto, de forma que el miedo se revierte en exigencias de normas ad hoc por parte del Estado para luchar contra la nueva amenaza criminal.

Esta "cultura de la emergencia"1 como respuesta al terrorismo internacional ha tenido como consecuencia la limitación del contenido de ciertos derechos fundamentales básicos a través la modificación de las legislaciones penales.

A este respecto, conviene recordar con Wildavsky/Dake que "las catástrofes desbordan los umbrales de percepción del peligro sobre los individuos, y que se imponen a cualquier agregación de peligros menores que pudiera resultar de un monto final mayor de amenaza", es decir, que la fuerza simbólica de las grande catástrofes se convierte en miedo y en necesidad de nuevas normativas especificas ${ }^{2}$.

De esta manera, la idea de defensa ha experimentado un tránsito hacia la de seguridad y propicia la aceptación sin límites de un modelo penal y procesal funcional a la defensa del Estado y la ausencia de principios liberales, que ha llegado a convertir el Derecho penal en "Derecho penal del enemigo", según la tesis propuesta y defendida por Gunther Jakobs.

Así, el terrorista que rechaza el principio de la legitimidad del ordenamiento jurídico y que persigue la destrucción del orden establecido por el mismo, comete un auténtico acto de guerra ${ }^{3}$, y no le puede ser aplicada la categoría de delito referida a las personas, en cuanto el terrorista no puede participar de los beneficios de los que son ciudadanos. En consecuencia, si no se quiere privar al Derecho penal del ciudadano de sus cualidades vinculadas a la noción de Estado de Derecho, "debería llamarse Derecho penal del enemigo a lo que haya que hacer contra los terroristas si no quiere sucumbir"4.

Esta idea no es en absoluto nueva, en cuanto tiene precursores filosóficos, como Rousseau y Fichte, que fundamentan el Estado de modo estricto mediante un contrato. Los que hacen delitos

\footnotetext{
1 BERGALLI "Libertad y seguridad: un equilibrio extraviado en la Modernidad tardía", en el derecho ante la globalización y el terrorismo: "cedant arma toga". Actas del Coloquio Internacional Humboldt, Montevideo abril 2003 coord por Losano/Muñoz Conde, Tirant lo Blanch Valencia, 2004, pág. 59-78.

2 WILDAVSKY y DAKE, "Theories of Risk Perception: Who Fears what and why?" Daedalus Vol. 119 (4), 1990, págs. 41 y ss.

3 LUIGI FERRAJOLI, " Due ordini di politiche e di garanzie in tema di lotta al terrorismo", gli speciali di Questione Giustizia "Terrorismo internazionale, politiche della sicurezza, diritti fondamentali", settembre 2016.

4 GUNTHER JAKOBS" ¿Terroristas como personas en Derecho?, Jakobs/Cancio, Derecho penal del enemigo, Civetas, 2006, págs. 57 y ss.
} 
infringiendo el contrato, ya no pueden vivir con los demás dentro una relación jurídica.

En particular Rousseau afirma que el culpable debe morir más como un enemigo que como un ciudadano ${ }^{5}$, y igualmente Fichte argumenta que quien abandona el contrato como ciudadano pierde todos sus derechos como miembro de un Estado y en general como ser humano y pasa a un estado de ausencia completa de derechos ${ }^{6}$.

Sin embargo,Jakobs desarrolla este pensamiento de manera diferente, acercándose más a la ideología de Hobbes y Kant, en cuanto no actúa una separación radical entre el ciudadano y su derecho, por un lado, y enemigo, por otro, sino que afirma que un ordenamiento jurídico debe mantener dentro del derecho también al criminal por una doble razón: porque el delincuente tiene derecho a volver a arreglarse con la sociedad $-y$ por ese motivo necesita mantener su status de ciudadano- y porque tiene el deber de reparar el mal hecho a la sociedad.

En este sentido, ya Hobbes $^{7}$ afirmaba que un ciudadano no puede quitarse su status por sí mismo, sino a través un acto de rebelión, como cuando cumple el delito de alta traición, que lo trae al estado de naturaleza. Kant ${ }^{8}$, en su escrito "Sobre la paz eterna" afronta el problema de cuando se puede legítimamente proceder de modo hostil contra un ser humano, considerando que quien no participa del estado comunitario-legal, minando la seguridad, debe irse y se le debe considerar como enemigo. Por tanto, ya Hobbes y Kant conocían y habían teorizado la diferencia entre derecho penal del ciudadano, contra personas que no delinquen de modo persistente, y derecho penal del enemigo contra individuos que cometen sistematicámente delitos y ponen en peligro la seguridad de la sociedad.

Siguiendo esa idea, Jakobs considera que el Estado moderno debe ver al delincuente como un ciudadano que ha dañado la vigencia de la norma y que es llamado a equilibrar este daño a través la pena, con dos presupuestos: el primero,que la norma determine la configuración de la sociedad, lo que significa que los demás deben adecuar su comportamiento a la norma a través una suficiente seguridad cognitiva, es decir que la norma debe tener el poder de conducir el comportamiento de los ciudadanos; el segundo, concierne a la personalidad del autor del hecho delictivo y su capacidad cognitiva mantenerse de modo contra fáctico.

Por lo tanto, quien se comporta así en el estado de naturaleza no recibirá del Estado un tratamiento como si actuara en el estado civil. Aquel que se comporta de manera permanente por fuera del pacto social no recibirá un tratamiento dentro de él.

\footnotetext{
${ }^{5}$ Véase ROUSSEAU, "El contrato social", Lib.II, cap.V.

${ }^{6}$ Véase FICHTE, "Grundlage des Naturrechts", capítulo 20.

7 HOBBES, "El ciudadano", cap.I.

8 KANT, "Sobre la paz perpetua".
} 


\section{1.- La criminalización del estadio previo}

En este sentido, Jakobs confirma la existencia de institutos de derecho penal que permitían la anticipación de la tutela penal en el Estado de derecho. En su trabajo, parte de la base de la inexistencia de un desarrollo dogmático coherente en Alemania que permita enfrentar las tendencias a la criminalización del estadio previo, en cuanto hay una contradicción entre principios generales e institutos de derecho penal como la tentativa de participación. Para el autor, en el contexto del código penal, el concepto de consumación es un concepto apenas formal, es decir que la consumación se orienta a formulación del tipo, no a criterios materiales, y en correspondencia con ello resulta materialmente inseguro determinar en términos generales que es el estadio previo.

Sin embargo, más allá de las consideraciones de tipo dogmático, aquello que a juicio de Jakobs permite una anticipación de punibilidad es una concepción errada del principio de la protección de los bienes jurídicos, entendido como protección de la integridad social y preservación a ultranza de los bienes jurídicos. La consecuencia es que la intervención penal se hace extrema y el delincuente deja de ser concebido como sujeto portador de una esfera de derechos que deben permanecer protegidos frente al acción penal. Consecuentemente el sujeto activo de la conducta puede ser definido tan solo por el hecho de que puede constituir un peligro para el bien jurídico, convirtiéndose en un enemigo del bien jurídico y perdiendo su libertad, derechos y garantías. La persona es juzgada en virtud de su peligrosidad y no por aquello que efectivamente ha cometido, la amenaza es el criterio penal para la intervención penal, desestructurándose así incluso la relación entre los propios ciudadanos ${ }^{9}$.

Si no existiera una diferenciación entre derecho penal del ciudadano y del enemigo, el ciudadano vería amenazada su esfera de derechos por la anticipación del estadio previo, violando el principio "cogitationis poenam nemo patitur"; en particular, una intromisión del Estado en la esfera privada contribuye o sirve seguramente a la protección de bienes jurídicos, pero por esta protección el autor tiene que ceder una parte de su esfera interna, de su libertad, que no puede pertenecer al derecho penal del ciudadano, sino del enemigo.

Es decir, la realización del principio de libertad se sitúa en el centro de la tensión entre derecho penal del enemigo y del ciudadano, donde el ciudadano es un sujeto cuya órbita privada no puede ser invalidada, mientras que el enemigo es un sujeto que pone en peligro los bienes jurídicos.

\footnotetext{
${ }^{9}$ GUNTHER JAKOBS, Fundamentos de derechos penal "Criminalización en el estadio previo a la lesión de un bien jurídico". Trad. de Enrique Peñaranda, Buenos Aires, 1996, pag. 182.
} 
Para concluir se puede decir que el delincuente de carácter cotidiano no debe ser tratado como un individuo peligroso, sino como una persona que ha actuado erróneamente. Por el contrario, un delincuente que está imbricado en una organización criminal, que rechaza los principios del orden jurídico y quiere destruirlo, necesita de un tratamiento penal diferenciado, en cuanto se correría el riesgo de privar al derecho penal del ciudadano de sus calidades vinculadas a la noción de estado de derecho para luchar contra enemigos que ponen en peligro constante el Estado ${ }^{10}$.

En otra palabras, la idea de Jakobs legitima la creación de un derecho penal y procesal desformalizado y despojado de garantías y principios, en el que rige, no la evitación de resultados lesivos, sino la persecución de la condición de autor, de la maldad y de los enemigos del ordenamiento jurídico, justificando de esa manera la renovación de la tortura como mecanismo de control y sometimiento; en definitiva,un derecho penal para la lucha contra el terrorismo que comporta la pérdida de eficacia de los principios que dominaron el panorama político - criminal y dogmático del siglo XX en Europa ${ }^{11}$.

Así,en numerosos Estados se crean tribunales especiales para el enjuiciamiento de los delitos de terrorismo y criminalidad organizada, se prolongan los tiempos de detención policial, se limita la elección de asistencia letrada, se limita el alcance de las comunicaciones del detenido o se amplían las competencias policiales en la práctica de ciertas diligencias de investigación; por lo tanto, se minimizan las garantías procesales derivadas de los derechos fundamentales a la libertad y a la tutela judicial efectiva. ${ }^{12}$

10 MARCO PELISSERO "Contrasto al terrorismo internazionale e il diritto penale al
limite", gli speciali di Questioni Giustizia "Terrorismo internazionale Politiche della
Sicurezza Diritti Fondamentali", settembre 2016 .
11 HÉCTOR OLASOLO ALONSO, ANA ISABEL PÉREZ CEPEDA "Terrorismo
internacional y conflicto armado", Tirant lo Blanch "colección los delitos", Valencia
2008 . Prefacio páginas 19 a 23 .
12 A este respecto, un ejemplo significativo es la USA Patriot Act del 26 de octubre
2001 que fortaleció los poderes de la policía sobre la sociedad civil, autorizando
toda la delegación facultada a entrar o secretamente en cualquier casa negocio,
recoger elementos de prueba para utilizarlos para ejercitar la acción penal;
cualquier agente puede controlar el tráfico de internet y los correos electrónicos, así
como interceptar los teléfonos celulares de millones de sospechosos; cualquier
agencia de policía federal puede invadir locales comerciales y confiscar todos los
registros sobre la base de que ese procedimiento está conectado con una
investigación sobre el terrorismo; se pueden detener personas sin comunicarles los
cargos, ni designarles abogado, sin límites temporales, etc. Además el presidente
Bush el 13 noviembre del 2001 emitió la "Military Order" que autoriza el gobierno
de los Estados Unidos a arrestar a los no-ciudadanos sospechosos de ser terroristas
y procesarlos en un tribunal militar. Los juicios son secretos y los fiscales no están
obligados a presentar pruebas si esto es "en pos de los intereses de la seguridad
nacional". Otro paradigma es la negación de estatuto jurídico a los prisioneros
recluidos en Guantánamo, en cuanto se les considera como combatientes ilegales
de manera que ni se la aplica la legislación procesal ordinaria de los Estados Unidos
ni la normativa de los Convenios de Ginebra 1949, para prisioneros de guerra. En
consecuencia, ni se les reconoce ninguna garantía constitucional, ni tan siquiera el 
Como ha subrayado Brandariz García, "el riesgo de amenaza, generalmente en forma de enemigo, es presentado, y vivido como un emergencia, como un peligro el que hay que responder de forma urgente y excepcional" ${ }^{\prime 13}$.

Sin embargo, esa excepcionalidad se convierte en normalización, en cuanto el concepto de excepcionalidad se une a la idea de transitoriedad y limitación en el tiempo, mientras que en la actualidad las normas que limitan los derechos fundamentales para luchar contra al terrorismo acaban convirtiéndose en la forma de tratamiento general y normalizada.

Se cae así en el peligroso error de pensar que, a través la democracia y los pilares del Estado de derecho y el derecho penal del ciudadano, no es posible luchar contra al terrorismo, olvidando que en un Estado democrático la seguridad de los ciudadanos no puede entenderse nunca como legítima si se realiza a costa de la libertad o de los derechos humanos básicos de algunos de ellos, como la ideología, las creencias religiosas o la nacionalidad.

Esta crisis de las democracias tiene diferentes consecuencias como el antagonismo entre los débiles; incomunicación entre diferentes sectores sociales; potenciar el miedo, las desconfianza y los perjuicios; devaluar los discursos de respeto a la dignidad y a la vida; dificultar la alternativa de solucionar realmente los conflictos; desacreditar los discursos limitadores de violencia; habilitar violencia para acabar con la violencia ${ }^{14}$.

\section{2.- LA TEORÍA DEL FINALISMO}

A este respecto y antes de profundizar en el concepto de derecho penal del enemigo, es interesante considerar "la expansión"15 del derecho penal de los últimos años para comprender el desarrollo del derecho penal del enemigo y también la teoría del finalismo como método sintético real-normativo para construir la responsabilidad penal.

Por un lado, conviene subrayar que las actividades legislativas en materia penal desarrolladas por los países occidentales se han basado en la promulgación de un conjunto de normas penales que anticipan la criminalización de un determinado comportamiento para

derecho a plantear un recurso antes los tribunales ordinarios norteamericanos, por que serán juzgados por una comisión militar, y se utilizan métodos de persuasión como la tortura.

13 BRANDARIZ GARCÍA, "Itinerarios de evolución del sistema penal como mecanismo de control social en las sociedades contemporáneas", en Nuevos retos del Derecho penal de la globalización (dir. Faraldo Cabana), Valencia, 2004, p. 59.

14 ZAFFARONI, PLAGIA y SLOKAR, "Derecho penal. Parte general" EDIAR, Buenos Aires, 2000, pág.17.

15 Un término utilizado por Silvia Sánchez en una monografía dedicada a caracterizar en su conjunto la política criminal de las sociedades post-industriales "la expansión del derecho penal. Aspectos de política criminal en la sociedad postindustriales" - primera edición 1999, segunda edición 2001. 
garantizar la protección de determinados bienes jurídicos desde el riesgo sufrir una lesión, este fenómeno consta de dos conceptos,el derecho penal simbólico y el resurgir del punitivismo.

El primero comprende aquellos fenómenos de nueva criminalización que tienen solo efectos simbólicos, es decir, el legislador crea sospecha de peligro y a través la ley da la impresión ser atento y decidido, infligiendo una pena para un daño que es más simbólico que real. Un ejemplo esclarecedor al respecto es la criminalización de meros actos de comunicación, como los delitos de instigación al odio racial o los de exaltación o justificación de autores de determinados delitos, o como el caso en España del delito de enaltecimiento del terrorismo ${ }^{16}$.

El segundo, por su parte, es la consecuencia de un proceso de criminalización que lleva a la legislación penal el fenómeno tradicional del populismo, asistiéndose a un cambio de actitud de la izquierdatradicionalmente descriminalizadora- que pide un anticipación de la tutela penal en caso de delitos de discriminación o cuando las víctimas son mujeres maltratadas; por otro lado, también la derecha se afirma como progresista-defensora en materia penal para lograr matices políticos a través la ideología de la "ley y orden".

Los dos fenómenos aquí descritos están estrechamente conectados, en cuanto el derecho penal simbólico no hace referencia a un grupo de infracciones penales bien definido, sino que identifica un especial significado simbólico del proceso mismo de criminalización según la especial importancia otorgada por el legislador. Por tanto, no atañe solo un hecho criminal, sino un tipo de autor para el cual son necesarios los trazos de un punitivismo exacerbado, de forma que el principio de legalidad y el principio del hecho dejan de ser un punto de referencia esencial para la tipificación penal.De la unión de estas dos ideologías surge el derecho penal del enemigo.

Por otro lado, el derecho penal del enemigo esta conectado con el concepto de responsabilidad penal que se basa en el método del finalismo, consistente en la contemplación de la función y de los fines del derecho penal, identificando los fenómenos reales que interesan al derecho penal, analizándolos en su estructuras, con el fin de conocer el fenómeno en su unidad y en su realidad para poder fundirlo con los valores jurídicos correspondientes ${ }^{17}$.

Como afirmaba Welzel, el autor más influyente de esa tesis, el respeto de determinadas estructuras fenoménicas de la materia del derecho por el legislador y la congruencia de la regulación jurídica con dichas estructuras lógico-objetivas, constituyen aquellas condiciones de la posibilidad de realización de la función y de los

\footnotetext{
16 AMNESTY INTERNATIONAL 2017, "Dangerously disproportionate - the everexpanding national security state in Europe", pág. 25.

17 LUIS GRACIA MARTÍN, "El horizonte del finalismo y el derecho penal del enemigo" pag 41 a 86. Tirant lo Blanch 2005.
} 
fines del derecho en general y del derecho en particular, en cuanto una vez que sea formada la sociedad, los seres humanos desarrollan su existencia en relación con dos mundos diferentes-natural y socialno necesariamente incompatibles, y ordenados según normas.

Las leyes del mundo físico natural son de carácter necesario. Por el contrario, las leyes sociales se fijan mediante convenciones entre los hombres y a través de un poder superior imponen deberes para que sean respetadas, permitiendo que los hombres adquieren la condición de personas responsables, dirigiendo sus actividades a una meta, obligándose a nivel ético-social y cumpliendo las obligaciones que han contraído. Por lo tanto el derecho penal, que regula la conducta humana, tiene que atenerse a esa estructura final de la acción humana, definida lógico-objetiva ${ }^{18}$, por las cuales se construye una responsabilidad penal finalista que considera la culpabilidad como capacidad individual de autodeterminación conforme al derecho; y donde no hay ninguna separación absoluta entre realidad y la norma ${ }^{19}$.

De hecho, para el finalismo la función y los fines del derecho penal son el punto de partida, en cuanto el derecho penal influye en los hombres que realizan determinadas conductas, evitando así consecuencias lesivas.

\section{1- El elemento subjetivo}

Consecuentemente, puesto que cualquier norma reguladora de conductas humanas tiene como objeto las acciones finales, de aquí resulta que la voluntad (dolo-culpa) de realización tiene que ser ya objeto de la anti-juridicidad y del concepto de injusto, es decir es parte del elemento objetivo; según la dogmática finalistica del tipo injusto el elemento subjetivo del hecho punible no es elemento distinto del objeto.

En sentido contrario, la dogmática actual sigue un esquema del hecho punible compartido en 3 elementos tipicidad, anti-juridicidad, culpabilidad donde la acción final contenida en la norma representa el hecho típico, la anti-juridicidad es la acción real que viola la norma penal, y la culpabilidad es el elemento subjetivo.

Según Luís García Martín, defensor de la teoría finalista, la división del tipo en una parte objetiva y en otra subjetiva es solo una exigencia del aspecto analítico del método jurídico de analizar el hecho punible, en cuanto materialmente los dos elementos objetivo y subjetivo se encuentran fundidos en una única unidad, ya que sin considerar el contenido de la voluntad del autor no se puede determinar el tipo objetivo de delito realizado por el autor. Además, para el finalismo la voluntad (dolo) y la finalidad de la acción no son

\footnotetext{
18 Véase M. ANGELES RUEDA MARTÍN, "La teoría de la imputación objetiva" p.416.

19 Véase JAKOBS, "Sociedad, norma y persona en una teoría de derecho penal funcional" trad. de Manuel Cancio Meliá $1^{\circ}$ edición, Madrid 1996.
} 
conceptos coincidentes, en cuanto la finalidad es la voluntad de realización de la acción, mientras el dolo es voluntad de realización del tipo delictivo. Para concluir, el finalismo reconoce dos tipos de voluntades y no niega los tres elementos que componen el hecho punible según la dogmática actual (tipicidad, anti-juridicidad y culpabilidad).

Por otro lado, los juicios de la tipicidad y de lo injusto, aunque tienen en el finalismo un componente normativo, comprenden acciones finales que deben ser valoradas como socialmente inadecuadas.

Para el finalismo lo injusto material que acota los tipos del derecho penal se forma y constituye en virtud y como resultado de diversas ponderaciones normativas relativas a las funciones sociales que desempeñan los bienes jurídicos, en cuanto solo hay bienes jurídicos en la medida en que cumplen una función social y producen efectos en la vida social. En este sentido, toda la vida social consiste en el uso y consumo de bienes jurídicos, pero el derecho puede dispensar protección a los bienes jurídicos únicamente frente a determinadas clases de acciones que pueden producir un daño que sobrepasa la medida, es decir, que afecta de manera grave estos bienes.

Así Jakobs confirma su teoría afirmando que el legislador debe actuar atacando un sujeto peligroso antes de que cometa el hecho, buscando como único interés la pretendida seguridad de los ciudadanos. Así, el derecho penal del enemigo se caracteriza por: 1) una amplia anticipación de la tutela penal en cuanto a la definición de las conductas punibles que llega al punto de castigar en ocasiones conductas de contenido simbólico en lugar de hechos, como delitos de sospecha que se apoyan en estructuras de peligrosidad sin necesidad de exteriorización de una conducta delictiva;2) el no respeto al principio de proporcionalidad, es decir sancionar de igual modo los actos preparatorios que los consumados;3) la relajación y supresión de determinadas garantías procesales individuales, como la presunción de inocencia, la reducción de las exigencias de admisibilidad de la prueba, la extensión del alcance de la intervención de las comunicaciones y de la investigación bajo secreto de sumario, la eliminación del principio nemo tenetur se ipsum accusare, la ampliación de los plazos de detención oficial con fines supuestamente investigadores ${ }^{20}$.

Es importante subrayar que cuando se habla de derecho penal del enemigo no se entiende una esfera aislada respecto al derecho penal del ciudadano, en cuanto ambos son solo dos tendencias opuestas, son conceptualmente diferentes, pero hacen parte de un

${ }^{20}$ GUNTHER JAKOBS, "La auto comprensión de la ciencia del derecho penal frente a las exigencias de su tiempo". (Comentario) En la ciencia del Derecho penal ante el nuevo milenio (coord. Versión española, Muñoz Conde), en Tirant lo Blanch, Valencia, 2004, págs. 58 y ss. 
único contexto jurídico penal, que se superpone. Esa idea es muy clara en el concepto de pena y en particular en la idea de pena estatal para Gunther Jakobs.

\section{3.- EL CONCEPTO DE PENA}

Normalmente la pena es coacción, en cuanto respuesta a un hecho cometido por parte de una persona racional que viola la norma $y$, por tanto, la pena garantiza que esa norma sea aún vigente, prevención general positiva; sin embargo, la pena tiene también el fin de la prevención especial, que evita la comisión de otro hecho delictivo a través la privación preventiva de la libertad, aplicándose así contra el individuo peligroso, como el caso de las medidas de seguridad como la custodia de seguridad, que se aplica por el hecho pasado que todavía debe ser sometido a juicio, pero se dirige al futuro por la tendencia de la persona a cometer hechos delictivos ${ }^{21}$.

\section{1.- Primera fase de la teoría de Jakobs}

De manera diferente, Jakobs, partiendo de la teorización de la noción de pena, llega a la definición del concepto de derecho penal del enemigo. En particular, en su obra sobre el significado y finalidad de pena estatal toma en consideración la teoría de diferentes filósofos sobre la noción de pena. Realiza una crítica a Hugo Grocio, que por su parte hace referencia a Séneca, Platón y Protágoras afirmando que ningún hombre inteligente castiga porque se ha cometido un infracción (quia peccatum est), sino para que no se vuelva a cometer (ne peccetur). No dice nada sobre la medida de la pena.

En particular Grocio asevera que no se puede eliminar lo que ha sucedido en el pasado, pero se puede evitar que suceda en el futuro. Por tanto, el fin de la pena no es la venganza, sino la mejora del autor cuando ésta sea posible, llegando si es necesario a la ejecución, así otros no sean inducidos al delito pensando que no sea sancionado. La pena es parte de un orden normativo legitimado en un orden estatal y que se basa sobre el principio que los seres humanos no persiguen exclusivamente su beneficio, en cuanto tienen un instinto de sociabilidad.

Según Jakobs, ni siquiera Hobbes llega a una solución diferente en cuanto que, considerando que el estado de naturaleza y no el estado de derecho ofrece el fundamento y límites de la pena a través reglas de prudencia, tampoco define la medida de la pena. Grocio y Hobbes explican por qué "ne peccetur", pero no aclaran el "quia peccatum est". Ambos afirman que se castigue para que no se vuelva a cometer, el fin de la pena es evitar que se cumpla en el futuro un delito.

21 GUNTHER JAKOBS y MANUEL CANCIO MELIÁ "Derecho penal del enemigo" segunda edición - Thomson civitas, págs. 23 a 27. 


\subsection{1.- Kant y Fauerbach}

En contra Kant y Fauerbach afirman que el fin de la pena es castigar el hecho delictivo (quia peccetum est). En primer lugar, critican la idea de un desacoplamiento entre la juridicidad que representa el estado de derecho y la prudencia del estado natural, ya que crearía dos problemas fundamentales: 1) sobre la existencia de una pena que se aplica en caso de violación de reglas de prudencia y también por razones jurídicas; 2) y si en el estado de derecho existe una pena que no pueda considerarse prudente.

Kant responde afirmando que la pena aconsejada por la prudencia no puede ser impuesta por razones jurídicas porque sería ilegítimo perseguir una utilidad con la pena sin que jurídicamente se hubiera establecido cual es la pena merecida.

Respecto al segundo problema, contesta positivamente en cuanto una vez que se ha encontrado al delincuente digno de castigo, debe ser castigado sin tomar en consideración ponderaciones de prudencia, porque la ley penal es un imperativo categórico y la pena tiene una finalidad preventiva dirigida al aseguramiento de derechos, y el merecimiento de la misma va asociado a la infracción de la ley.

Por lo tanto, se plantea la cuestión de si la retribución fundamenta el deber de castigar de la sociedad civil o es solo una autorización para el castigo. Consecuentemente, sí se podría entender como admisible una renuncia a la pena o a una parte de la pena siempre que dicha renuncia no conlleve la lesión de los derechos de otros, en especial cuando no conlleve tampoco lesión alguna del principio de igualdad ni peligro para la estabilidad del ordenamiento jurídico, perdonando al delincuente juvenil con medida educativa o al que delinque por primera vez con la suspensión condicionada de la pena.

En Kant, la idea de una vinculación necesaria entre delito y pena no se encuentra aislada, sino conectada al concepto de merecimiento de la felicidad en cuanto las obras buenas merecen premio. De esta forma, por lo tanto, la pena sería impuesta no como consecuencia de todo delito, sino solo de aquellos que se convirtieran en saldo negativo; en esa situación carece de toda plausibilidad la exigencia de proceder categóricamente, más bien parece que no debería imponerse una pena justa que carezca de un motivo útil.

Solo el derecho de retribuir con el mismo mal puede determinar de forma concreta la calidad y cantidad de la pena.

Según Jakobs el límite de la teoría de Kant es el concepto de pena como imperativo categórico, entendido como delito igual a pena, sin tomar en consideración fines e intereses.

El pensamiento kantiano es compartido por Feuebach, que afirma que el derecho trata de la determinación de la libertad, en contraposición a la moral como ámbito de los deberes. Consecuentemente, el reconocimiento de un deber por la razón obliga 
a la voluntad a realizar una conducta conforme, en tanto que, a través el sistema de los derechos, el albedrío puede elegir entre fines y acciones contrapuestos.

Partiendo de esta idea, Feuerbach considera que los derechos de una persona son todos los que no afecten a los derechos de otros, es decir a su libertad, que en el estado de derecho se traduce en la libertad reciproca de todos los ciudadanos. Sin embargo, Feuerbach llega a una conclusión diferente de la de Kant sobre el concepto del fin de la pena, afirmando que cada ofensa contradice la naturaleza y finalidad de la asociación de los ciudadanos y es necesario que quede absolutamente excluida cualquier ofensa dentro del estado. En cuanto este último no puede físicamente encadenar a todos los ciudadanos, tiene lugar el uso de una cadena o coacción psicológica como la amenaza penal con la cual el ciudadano sabe con seguridad que cada infracción tiene como consecuencia un mal mayor.

Desde la idea común de que el fin de la pena es castigar el hecho delictivo, desarrollan una teoría de los fines de la pena diferente, Kant como retributiva y Feuerbach como coacción psicológica, acabando por definir la medida de la pena como la relación entre el daño que sufre la víctima/pena, y no hecho/ pena.

\subsection{2.- Hegel}

En un sentido diferente, Hegel afirma que el delito actúa contra la estructura social y entonces contra el derecho, que es la libertad entendida como espíritu activo y representado en tres novedades:

1. Derecho abstracto- la persona en derecho en cuanto propietario;

2. Moralidad- la exigencia frente al derecho de tener en cuenta la subjetividad;

3. Eticidad - la generalización de la libertad de los sujetos en instituciones, familia, sociedad civil y estado.

En la primera dimensión del derecho, como abstracto, no se resuelve la cuestión del por qué se elige infligir el dolor y no otras cosas, ni se responde a la cuestión de la medida de la pena, sino que se afirma solo que el delito es vulneración del derecho y la pena salvaguardia la realidad jurídica puesta en peligro por el hecho, confirmando la vigencia de la norma 22.

En la dimensión real, el delito es coacción ejercida como violencia por el sujeto libre que lesiona la existencia de la libertad, en cuanto el autor lesiona el principio del respeto frente a las esferas de la libertad ajenas.

En consecuencia, al autor se le suspende total o parcialmente como destinatario y emisor en la comunicación, porque se le ejecuta o se le impide el uso de sus facultades encerrándolo, $y$, a través del dolor de la pena se le provocan determinadas reacciones individuales

22 GUNTHER JAKOBS, "La Pena Estatal: Significado y Finalidad", trad. de M. Cancio Meliá, B. Feijo Sánchez, Thomson Cuadernos 2006, págs. 129-135. 
o psicosociales, es decir, una reducción de la motivación delictiva, un instrumento de dirección o un equivalente del hecho malo.

Hegel desarrolla el concepto de realidad del derecho, que no puede garantizar la libertad e impedir todo el abuso de la libertad, porque supondría una vigilancia de dimensión totalitaria, lo opuesto de la libertad. El estado de libertades debe garantizar y mantener un máximo de juridicidad, en un sistema en el cual el derecho está en vigor también cuando se produce una conducta anti-jurídica.

En este contexto, la finalidad cognitiva de la pena es mantener la vigencia de la norma para garantizar la fidelidad al derecho y la confianza en la norma de la gente fieles, que según la idea de prevención general positiva de Jakobs, no corresponde ni al "punitur, Ne peccetur" o al "punitur, quia peccatum est", siendo correlativa al concepto de prevención general negativa que considera el dolor penal con una finalidad de intimidación de los potenciales autores para garantizar la fidelidad en la norma.

Dicho de otro modo, la pena para mantener confianza en la norma, debe producir miedo o convicción, y solo en ese caso mantendrá esa confianza.

En conclusión, Jakobs, en esta primera fase, criticando a Fauerbach, y recomendando el concepto hegeliano de pena con finalidad cognitiva, afirma que para comprender la medida de la pena es fundamental contestar a la pregunta relativa a cuánto el hecho delictivo perturba la sociedad, subrayando la importancia del reporte entre hecho/ pena y no daño / pena.

Para evaluar este peso social es decisivo considerar 3 aspectos: 1) peso de la norma vulnerada y la medida de su vulneración; 2) la situación del aseguramiento cognitivo de la misma; 3) la responsabilidad del autor en relación a la motivación para la comisión del hecho, si es posible reconocer una exoneración parcial de la pena.

Sin embargo, la cuestión de la medida de la pena presenta mayor dificultad respecto de la prevención especial, el mejoramiento del autor mediante educación.

En ese caso, hay que distinguir entre un ser humano que, a través la educación, en el futuro pueda llevar una vida sin delinquir o en su lugar, un peligroso autor con tendencia a cometer hechos delictivos.

Como se infiere de la ley de tribunales de menores, para los delincuentes jóvenes corresponde dar prioridad al fin educativo.

A diferencia de la prevención general positiva, en la que se exige la reparación del autor para el hecho cometido y la medida es igual a hecho y pena; en el ámbito de la prevención especial mediante educación la medida de la pena debe ser adecuada a la culpabilidad. 


\section{2.- Segunda fase de la teoría de Jakobs}

En este sentido, Jakobs desarrolla una posterior teoría de la pena partiendo de una concepción psicológica de la misma como prevención general positiva, identificándola antes como el ejercicio en la fidelidad al derecho, actuar respectando el derecho, pero dando relevancia al aspecto más individual y psicológico y después como confirmación de la identidad y estabilidad de la sociedad, en cuanto la pena se debe entender como marginación del hecho delictivo y garantía de que la estabilidad normativa de la sociedad permanezca inalterada.

En esta segunda fase del pensamiento de Jakobs se puede considerar la pena como compuesta de dos funciones -abierta y latente-, y que la pena, en virtud de cada función, se dirige a un destinatario diferente. La abierta es confirmadora de la vigencia de la norma y se dirige a los participantes en la comunicación; la latente se dirige a delincuentes reales (prevención especial), a delincuentes potenciales (prevención general negativa) y a la fidelidad interna de los individuos (prevención general positiva) ${ }^{23}$.

En particular, se desarrolla el concepto de expectativas normativas, como elementos estructurales del sistema y con perspectiva de tener un determinado comportamiento más o menos estable. Por tanto, si una persona defrauda estas expectativas, infringiendo normas, la norma no se ve modificada solo porque existan defraudaciones, sino reacciona con una sanción; en consecuencia, en caso de defraudación, no hay que modificar la visión que se tiene del mundo, sino que las personas pueden tener una confianza firme en las mismas normas.

La pena, por tanto, se mueve en un plano simbólico o comunicativo y no puramente instrumental de protección de bienes jurídicos, en cuanto dirigida al restablecimiento y mantenimiento de la norma; el hecho delictivo es la negación de la estructura de la sociedad, la pena la marginalización de esa negación, y por tanto confirmación de la estructura, que se dirige a personas, a participantes en comunicación. La pena no debe ser entendida en el plano natural, como un mal que sucede a otro mal, sino comunicativamente, como restablecimiento de la validez de la norma.

Sin embargo, Jakobs en la ultima fase de su pensamiento subraya que básicamente la pena está orientada a la condena del hecho delictivo, en cuanto esa retribución tiene un significado positivo para la sociedad de cara al futuro para orientar las conductas, evolucionando así su pensamiento desde la teoría radicalmente

\footnotetext{
23 GUNTER JAKOBS, "La Pena Estatal: Significado y Finalidad", Thomson Cuadernos 2006, págs. $33-53$.
} 
preventiva hacia una teoría retributiva y funcional de la pena 24 , compartiendo la idea de Kant sobre el fin de la pena.

En la subsiguiente evolución de su teoría, Gunther Jakobs dedica su atención a los efectos preventivo especial y general negativo, en particular intenta explicar la necesidad del dolor penal y también la problemática del sujeto peligroso imputable desde la perspectiva del llamado derecho penal del enemigo.

Respecto al primer argumento, Jakobs afirma que el dolor penal, consiguiente a la pena, se determina en función de la intensidad de afectación que sea necesaria en el autor -pago y compensación- y por tanto se inflige un daño ya que solo así la empresa delictiva será considerada como fracasada. Ese concepto de pena excluye sanciones en clave preventiva general positiva para mejorar la vigencia de la norma y en clave preventiva general negativa sobre peligro futuro de comisión del hecho delictivo.

Por lo que concierne el segundo argumento, se toman en consideración determinados infractores que se apartan permanentemente del cumplimento de la norma, y que están en conflicto con el Estado de derecho, los cuales perdiendo las garantías de ciudadanos, como ya se ha dicho, estarán sometidos al derecho penal del enemigo. 25

Resumiendo, la pena teorizada en el contexto del derecho penal del enemigo según Jakobs tenía una finalidad preventiva para asegurar la vigencia de la norma y la medida de la pena era la repercusión negativa del hecho en la sociedad (violación de la norma / pena); en la segunda fase de su pensamiento se reconoce una finalidad retributiva de la misma para punir el hecho delictivo, considerando la medida en el binomio hecho/ pena.

La finalidad preventiva miraba solo al dato normativo, la violación de la norma tenía como consecuencia la pena sin considerar el elemento material del hecho en si mismo y excluyendo cualquiera consideración de la voluntad (dolo - culpa) del reo. Sucesivamente, Jakobs supera esta posición extrema y da valor al hecho como fin de la pena en clave retributiva aunque no dé importancia al elemento subjetivo.

\section{4.- CRITICA A LA TEORÍA DEL DERECHO PENAL DEL ENEMIGO}

Según Jakobs, el derecho penal del enemigo contenido en las legislaciones actuales es la consecuencia de la evolución del sistema jurídico - penal, es decir, no es el retorno a una política criminal autoritaria, sino una fase evolutiva nueva del mismo sistema, en

24 GUNTHER JAKOBS, "La pena Estatal: significado y finalidad", traducción de Manuel Cancio Meliá, Bernardo Feijoo Sánchez, Thomson - civitas 2006, págs. 28 a 38.

25 GUNTHER JAKOBS - MANUEL CANCIO MELIÁ "Derecho penal del enemigo" segunda edición - Thomson civitas. Pág. 119. 
cuanto el derecho penal moderno se ocupa de sujetos culpables que ponen en cuestión las características de la configuración de la sociedad, entendidos como ciudadanos equivocados, fuera de esta área, cuyos ataques de sujetos culpable no son delitos, sino actos de guerra que son sometidos a un derecho penal diferente.

La paz es la condición fáctica para el funcionamiento del derecho, donde hay guerra no hay Estado ni derecho, en cuanto la guerra no se puede considerar en un contexto jurídico.

Sin embargo, no faltan las críticas a esta teoría, el derecho penal del enemigo recuerda mucho el derecho penal de autor que propugnaron los nazis, según el cual lo relevante no era el hecho delictivo cometido, sino la inclinación al delito y la peligrosidad criminal del autor. ${ }^{26}$

Siguiendo esta idea, se afirmaba la existencia de dos derechos penales para diferentes seres humanos "personas" y "no personas", que durante el nacionalsocialismo eran diferenciadas para un dato biológico: la pertenencia o no a la raza aria como raza pura frente a otras razas que eran inferiores. La culminación de esta biopolítica fue el "campo de concentración", al que se destinaban los "impuros". Éstos, desde el punto de vista jurídico, por su consideración como "no persona", como no ciudadano, eran carentes, por lo tanto, de unos mínimos derechos ${ }^{27}$.

El filósofo italiano Giorgio Agamben, comentando la tesis de Carl Schmitt sobre la distinción amigo-enemigo y el concepto de estado de excepción, analiza el campo de concentración como paradigma biopolítico de lo moderno, afirmando que "unas de las características de los regímenes nazi y fascistas fue la separación del hombre como simple "vida desnuda", pura cosa viva sin derecho, y el hombre como ciudadano, como ser político y titular de derechos, según un criterio biopolítico, determinado por la sangre y la herencia genética. ${ }^{28}$

\footnotetext{
${ }^{26}$ Jakobs afirma "El enemigo es un individuo que, no solo de manera incidental, en su comportamiento, o en su ocupación profesional, o principalmente através de una organización, es decir, en cualquier caso, de una forma presuntamente duradera, ha abandonado el derecho y, por lo tanto, no garantiza el mínimo cognitivo de seguridad del comportamiento personal y demuestra este déficit a través de su comportamiento".

GUNTHER JAKOBS, "La ciencia penal ante los retos del futuro", en Eser/Hassemer/Burkhardt, La ciencia del derecho penal ante el cambio de milenio, trad. De Teresa Manso, cit., pág. 59.

27 El famoso penalista alemán Mezger, en los informes que redactó en 1943 para el régimen nacionalsocialista acerca de un proyecto de ley sobre el tratamiento de "Extraños a la Comunidad", decía que "en el futuro habrá dos derechos penales: 1) un derecho penal para la generalidad y otro para grupos especiales de determinadas personas." Véase texto de MUÑOZ CONDE "Edmund Mezger y el derecho penal de su tiempo", cit., pág. 236.

28 GIORGIO AGAMBEN, "Homo sacer. El poder soberano y la vida desnuda" Cit., págs. 147 y ss.
} 
Se trataba de un régimen totalitario, en el que se daba por sentado que existiera un derecho penal de este tipo para los "enemigos" y los "extraños a la comunidad". Pero una distinción similar es más difícilmente asumible en el Estado de Derecho, que, por definición, no admite que se pueda distinguir entre "ciudadanos" y "enemigos", en cuanto los derechos y garantías fundamentales propias del Estado de Derecho, sobre todo las de carácter penal material y procesal son presupuestos irrenunciables de la propia esencia del Estado de derecho. Si se admite su derogación, aunque sea un casos puntuales extremos y muy graves, se tiene que admitir también el desmantelamiento del Estado de Derecho, cuyo ordenamiento jurídico se convierte en un ordenamiento puramente tecnocrático o funcional, sin ninguna referencia a un sistema de valores, o, lo que es peor, referido a cualquier sistema, aunque sea injusto, siempre que sus valedores tengan el poder o la fuerza suficiente para imponerlo. El derecho así entendido se convierte en un puro derecho del estado, en el que los derechos se someten a los intereses que en cada momento determine el Estado o las fuerzas que controlen o monopolicen su poder.

Se tendrá una fundamentación del derecho penal del enemigo funcional al sistema democrático, aunque muchos preceptos no tengan nada de democráticos. En definitiva, la razón de Estado, que es lo que monopoliza el poder punitivo, o la funcionalidad de su sistema, independientemente de que sea democrático o autoritario, se convierte en el único fundamento del derecho penal.

\section{5.- CONCLUSIÓN}

Por lo tanto, el problema que debería plantearse el jurista con conciencia es la compatibilidad de los preceptos del derecho penal del enemigo con el Estado de Derecho. Se trata de ver hasta qué punto son legítimos, es decir, si están o no en consonancia con los principios del estado de derecho y respetan los derechos fundamentales reconocidos constitucionalmente 0 los derechos humanos de carácter internacional. Y efectivamente, muchas veces los tribunales constitucionales, han declarado la in-constitucionalidad de estos preceptos o han anulado condenas que se habían basado en los mismos ${ }^{29}$.

29 El Tribunal Europeo de derechos humanos ha manifestado repetidas veces que la
ley española de enjuiciamiento criminal es insuficiente porque no respeta los
principios de proporcionalidad (casos "Valenzuela" Y "Prado Bugallo").
Por su parte el Tribunal Constitucional Federal Alemán, en una sentencia del 3
marzo 2004, ha declarado inconstitucional la regulación que en 1999 había
introducido el legislador alemán en la ordenanza procesal penal, por la que se
permitían graves intromisiones empleando como medios de prueba grabaciones de
conversaciones en el ámbito de la intimidad más estricto, por no cumplir
determinadas garantías- requisitos derivadas de los principios de legalidad y de
proporcionalidad. Y el 16 de diciembre de 2004 , la Cámara de los Lores inglesa ha 
Como ya se ha considerado por influyente doctrina, Jakobs no especifica tres cuestiones importantes de su teoría, es decir,quienes son los enemigos, la compatibilidad de su pensamiento con el estado de derecho ${ }^{30}$ y como el ciudadano se convierte en enemigo. La tesis sobre el derecho penal del enemigo es ambigua y se limita a constatar una realidad, aludiendo a la necesidad de una "seguridad cognitiva" como fundamento de su existencia, que el describe como aspiración fundamental del derecho penal del enemigo y también como aspiración de cualquier sistema jurídico.

Pero una seguridad cognitiva total nunca puede ser garantizada por ningún sistema, sino que podrá haber niveles mayores o menores de seguridad, que plantean el problema de la compatibilidad de ellos con los derechos fundamentales. Por lo tanto, el equilibrio entre los dos polos del derecho penal (enemigo - ciudadano) es difícil.

Según algunos autores, se trata de una ambigüedad ligada a un lenguaje críptico e impenetrable, que se centraliza sobre la certeza cognitiva, sin la cual no sería aplicable el derecho penal del enemigo, en cuanto el enemigo tiene una especie de personalidad potencial y no se comporta como persona en el derecho; es decir, la certeza cognitiva que pueden prestar ciertos individuos se mide en función de su capacidad para generar una forma de violencia diferente, que amenaza las instituciones estatales, como el caso de la violencia terrorista.

Se trata de una tesis muy peligrosa sobre todo hoy por las tendencias radicales de derecha en Europa, con el problema del multiculturalismo, en cuanto puede desarrollarse un derecho penal

sentenciado que la ley anti-terrorista inglesa del 2001 patrocinada por el gobierno Blair, que permitía la detención gubernativa sin límite temporal de extranjeros sospechosos de terrorismo (una especie de Guantánamo británico) infringe entre otros derechos de la Convención Europea, el derecho a la igualdad jurídica entre extranjeros y ciudadanos, el debido proceso y el de protección judicial efectiva.

Dentro de la polémica de si admitir en el ordenamiento jurídico la exclusión de los derechos que reconocen por la constitución y textos jurídicos fundamentales a determinados sujetos que se consideran como "enemigos", parece interesante considerar las decisiones de la Corte Suprema de los Estados Unidos de Norteamérica en relación con la situación jurídica de los presos afganos en la base militar norteamericana de Guantánamo, Cuba, casos "Rasul", "Padilla", "Hamdi". El problema que se había planteado era si los presos tenían el derecho de solicitar un recurso contra su detención ante un juez norteamericano, según la norma del "habeas corpus que crearía jurisdicción de los tribunales federales en los supuestos de demandas realizadas por un ciudadano americano detenido en la Base. Para un juez, el mismo argumento que se había utilizado para admitir el recurso de uno de los presos -que era estadounidense- se podía utilizar para rechazar los otros recursos que no eran presentados por ciudadanos estadounidenses. Sin embargo, la opinión que prevaleció, afirmaba que los extranjeros detenidos en la Base tienen los mismos derechos al recurso de los americanos, en cuanto la norma no hace una diferenciación entre detenidos.

30 FRANCISCO MUÑOZ CONDE, "De nuevo sobre el derecho penal del enemigo", "algunas consideraciones sobre el derecho penal del enemigo".editorial Hammurabi s.r.l, 2005, pág. 70. 
racista y articulado sobre la persecución a sujetos excluidos en sociedades.

Si Jakobs tiene el mérito de haber manifestado la existencia del derecho penal del enemigo, también en los ordenamientos jurídicos de los Estados de derecho, en todo caso no se puede compartir su idea sobre la tarea del jurista como simple mensajero que se limita a transmitir malas noticias y no analiza críticamente su compatibilidad con determinados principios.

La tarea del jurista, del político y del intelectual en el estado de derecho es la definición de los derechos fundamentales que no puedan ser vulnerados en ningún caso y bajo ninguna circunstancia, aunque siempre habrá quienes les nieguen valores limitantes ${ }^{31}$. Sin embargo tanto a nivel nacional, con las constituciones, como a nivel internacional, con declaraciones vinculantes para los estados en pro del reconocimiento de un catálogo mínimo de derechos para todos los seres humanos, y la creación de la Corte Penal Internacional para sancionar los abusos más graves contra esos derechos, se ha desarrollado un sistema de controles y filtros contra cualquier uso abusivo del derecho penal ${ }^{32}$.

\footnotetext{
${ }^{31}$ BORTOLI, "Legislazione e prassi in tema di contrasto al terrorismo internazionale: un paradigma emergenziale?", Diritto Penale Contemporaneo, núm. 3, 2017.

32 Como decía Giorgio Agamben sobre el campo de concentración "seria más honesto y útil, indagar atentamente acerca de los procedimientos jurídicos y dispositivos políticos que hicieron posible llegar a privar tan completamente de su derechos a unos seres humanos hasta el punto de que el realizar cualquier tipo de acción contra ellos no se considerara ya como un delito". AGAMBEN, "Homo sacer. El poder soberano y la vida desnuda", cit., págs. 217 y ss.
} 